\title{
Third Shape Casting Symposium Foreword
}

The science of solidification and the technology of casting production, as twin waifs and strays, have over the years suffered erratic growth. This growth, perhaps slower on average than many might wish, has been the outcome of devoted researchers and foundry people during the past decades. Although often separated, when brought together, the coalescence of knowledge contributed by each twin promises the burgeoning of a fast growing and powerful, if not monumental, alliance.

Those adopting and nurturing our twins into maturity have the foundation of knowledge provided by books (although I personally believe I can legitimately claim to be the author of the world's most unread foundry textbooks), but in addition, they require regular updating by reading many of the world's excellent metallurgical journals. The correspondence columns of these journals are an education in the most recent thinking and are recommended to all. The current debates have the potential to create a sea-change in our approach to solidification and casting.

From my personal perspective, the wind of change blows especially strongly from the direction of those externally introduced defects in liquid metals that appear to control many of the aspects of microstructure and the mechanical and corrosion behavior of castings. Many of our researchers in the field of solidification continue to overlook the possibility that (1) entrained bifilms exist in their materials and (2) may actually be in control. The author is unrepentant for introducing this turmoil to our previously settled and contented lives. He maintains that our current science alone cannot explain either the structures or the property response of metallic materials, and that only extrinsic factors, particularly the endemic populations of bifilms, can develop our twins into a cogent science and an effective technology.

Time will tell. This symposium is yet another in our Shape Casting series in which these concepts, unloved by some, but welcomed by others, can be debated. Passion is permitted. But Truth is sought and, it is to be hoped, will prevail.

On this occasion, the symposium has been unusually problematic to organize as the result of several technical issues, and it is therefore appropriate to thank all our session chairs for the nontrivial task of reviewing submissions to their sessions. Above all, particular thanks go to Paul Crepeau and Murat Tiryakioglu, without whose monumental efforts this symposium would never have happened. Thank you, Paul and Murat.

John Campbell

University of Birmingham, Edgbaston, UK 